\title{
Accumulation of aberrant CpG hypermethylation by Helicobacter pylori infection promotes development and progression of gastric MALT lymphoma
}

\author{
TAKAMI KONDO ${ }^{1}$, TAKASHI OKA ${ }^{1}$, HIAKI SATO ${ }^{1,3}$, YOKO SHINNOU ${ }^{1}$, KANA WASHIO ${ }^{1}$, \\ MASAYUKI TAKANO ${ }^{1}$, TOSHIAKI MORITO ${ }^{1}$, KATSUYOSHI TAKATA $^{1}$, NOBUYA OHARA ${ }^{1}$, \\ MAMORU OUCHIDA ${ }^{2}$, KENJI SHIMIZU $^{2}$ and TADASHI YOSHINO ${ }^{1}$ \\ Departments of ${ }^{1}$ Pathology and ${ }^{2}$ Molecular Genetics, Graduate School of Medicine, \\ Dentistry and Pharmaceutical Sciences, Okayama University; ${ }^{3}$ Faculty of Health Sciences, \\ Okayama University Medical School, 2-5-1 Shikata-cho, Okayama 700-8558, Japan
}

Received February 12, 2009; Accepted April 27, 2009

DOI: 10.3892/ijo_00000366

\begin{abstract}
Aberrant DNA hypermethylation is an important mechanism for the inactivation of tumor-related genes in human tumors. Gastric mucosa-associated lymphoid tissue (MALT) lymphomas arise from Helicobacter pylori-associated chronic gastritis; most patients are H. pylori-positive and eradication therapy is highly effective. In the present study, we used methylation-specific PCR to analyze the DNA methylation status of 11 tumor-related genes (Kip2, p16, hMLH-1, p15, p73, MGMT, DAPK, MINT1, MINT2, MINT31 and $H C A D)$ in 21 specimens of MALT lymphoma, 5 specimens of MALT lymphoma with large cell component (high-grade MALT lymphoma), 15 specimens of diffuse large B-cell lymphoma (DLBCL), 8 specimens of complete remission of MALT lymphoma after eradication therapy, 5 specimens with no evidence of malignancy and PBMCs from 10 healthy donors. The average number of methylated genes was significantly greater in gastric lymphomas as compared to normal controls $(\mathrm{P}<0.001)$. The $\mathrm{CpG}$ island methylator phenotype (CIMP) was observed in $93.3 \%$ (14/15) of DLBCLs, $100 \%(5 / 5)$ of high-grade MALT lymphomas and $61.9 \%$ (13/21) of MALT lymphomas; in contrast, CIMP was not found in the control group $(0 \%)$. The average number of methylated genes and the CIMP incidence significantly increased with $H$. pylori infection. Furthermore, aberrant $\mathrm{CpG}$ methylation of specific genes, such as p16, MGMT and
\end{abstract}

Correspondence to: Dr Takashi Oka, Department of Pathology, Graduate School of Medicine, Dentistry and Pharmaceutical Sciences, Okayama University, 2-5-1 Shikata-cho, Okayama 700-8558, Japan

E-mail: oka@md.okayama-u.ac.jp

Key words: methylation, mucosa-associated lymphoid tissue lymphoma, methylation-specific PCR, Helicobacter pylori, progression
MINT31, was consistently associated with $H$. pylori infection. These findings strongly suggest that $H$. pylori infection causes the aberrant DNA hypermethylation of specific genes and induces CIMP, which is an important epigenetic mechanism for the development and progression of gastric MALT lymphoma; additionally, our findings provide new epigenetic markers.

\section{Introduction}

Mucosa-associated lymphoid tissue (MALT) lymphoma, a common low-grade B-cell lymphoma arising from a background of chronic inflammatory diseases at a number of mucosal sites, was first described by Isaacson and Wright in 1983 (1). MALT lymphomas originating in the stomach are causatively linked to Helicobacter pylori infection and eradication of the bacterium with antibiotics leads to longterm complete remission of the lymphoma in $\sim 70 \%$ of patients (2). Additional evidence links Campylobacter jejuni (3), Chlamydia psittaci (4), Borrelia burgdorferi (5) and hepatitis $\mathrm{C}$ virus $(6,7)$ infection with MALT lymphoma of the small intestine, ocular adnexa, skin and splenic marginal zone, respectively. These organs are normally devoid of organized lymphoid tissue and lymphoma. MALT lymphomas arise from these sites as a result of chronic inflammatory or autoimmune disorders, such as $H$. pylori-associated chronic gastritis, lymphoepithelial sialoadenitis, Sjögren syndrome and Hashimoto thyroiditis $(8,9)$. The common karyotypic alterations that characterize MALT lymphoma include the trisomies of 3 and $18(10,11)$ and the translocations $\mathrm{t}(11 ; 18)(\mathrm{q} 21 ; \mathrm{q} 21)$ $(12,13), \mathrm{t}(1 ; 14)(\mathrm{p} 22 ; \mathrm{q} 32)(14,15), \mathrm{t}(14 ; 18)(\mathrm{q} 32 ; \mathrm{q} 21)(10,16)$, and $\mathrm{t}(3 ; 14)(\mathrm{p} 14.1 ; \mathrm{q} 32)(17,18)$, which commonly activate the $\mathrm{NF}-\kappa \mathrm{B}$ pathway. The most common translocation is $\mathrm{t}(11 ; 18)$ (q21;q21), which results from the fusion of the API2 (apoptosis inhibitor 2) and the MALTl (MALT lymphomaassociated translocation) genes $(19,20)$. Clonal identities of the immunoglobulin heavy chains between low-grade MALT lymphomas and coexisting diffuse large B-cell lymphoma (DLBCL) have been found in a considerable number of 
patients, indicating that low-grade MALT lymphoma progresses to high-grade malignancy composed of largesized lymphoma (DLBCL) $(21,22)$. The detailed molecular mechanism of the progression to high-grade lymphoma has not been elucidated.

Genetic abnormalities found in various cancers do not provide the complete picture of molecular mechanism of cancers and malignancies. Epigenetic changes, mainly DNA methylation and histone modification, are additional mechanisms that contribute to the malignant phenotype (23-25). DNA methylation is a normal process used by mammalian cells in maintaining a normal expression pattern; it is involved in the regulation of imprinted gene expression and $\mathrm{X}$-chromosome inactivation and in the fine-tuning of specific differentiation of cells and the development from stem cells (26-29). However, aberrant promoter hypermethylation of the $\mathrm{CpG}$ islands leads to epigenetic silencing of multiple genes, including tumor suppressor genes and has been recognized as an important mechanism in carcinogenesis (30-32). Furthermore, concordant promoter hypermethylation of multiple genes, the $\mathrm{CpG}$ island methylator phenotype (CIMP), has been found in gastric and colorectal carcinomas (33-35).

Our goal in the current study was to clarify the contribution of epigenetic abnormalities to disease development and progression. We comparatively evaluated the methylation status of 11 genes in gastric lymphomas and related diseases (MALT lymphoma, high-grade MALT lymphoma and DLBCL) and a control group that included complete remission specimens of MALT lymphoma after eradication therapy, specimens of no evidence of malignancy in the stomach and healthy donor peripheral blood mononuclear cells (PBMCs). In addition, we addressed the questions of whether CIMP is associated with gastric lymphoma development and/or progression.

\section{Materials and methods}

Specimens. Specimens were pathologically diagnosed at Okayama University Medical School from 1989 to 2000; there were 21 specimens of primary gastric MALT lymphoma (low-grade MALT lymphoma; L-MALT), 5 specimens of gastric MALT lymphoma with large cell component (highgrade MALT lymphoma; H-MALT) and 15 specimens of gastric DLBCL. The control group contained specimens from: 8 patients of complete remission (CR) of gastric MALT lymphoma after eradication therapy; 5 patients of no evidence of malignancy (NEM) in the stomach with infiltration of mononuclear cells, including chronic gastritis and 10 healthy donors of PBMCs. Informed consent was obtained from all patients and healthy volunteers. All the patient-derived materials in the present study were used following the guideline of Japanese Society of Pathology. All tissue samples were obtained by endoscopic biopsy with surgical resection followed by immediate freezing and storing at $-80^{\circ} \mathrm{C}$. High molecular weight DNA was extracted by the phenol/chloroform method.

Sodium bisulfite modification and methylation-specific PCR (MSP). Sodium bisulfite modification of DNA was performed, as previously described $(31,32)$. Briefly, $1 \mu \mathrm{g}$ aliquots of genomic DNA were denatured by $\mathrm{NaOH}$ and modified by sodium bisulfite, which converts all unmethylated cytosines to uracils while leaving methylated cytosines unaltered. Modified DNA was purified, desulfonated with $\mathrm{NaOH}$, precipitated with ethanol and resuspended in TE buffer. The methylation-specific PCR was performed to examine the methylation status of 11 tumor-related genes: cell-cycle regulators (Kip2, p16, p15) (36,37), mismatch repair (MGMT) (38), DNA repair (hMLH-1) (39), tumor suppressor ( $p 73)(40)$, apoptosis $(D A P K)(41)$, cell adhesion [HCAD (CDH13)] (42) and methylated in tumor (MINT1, MINT2, MINT31) $(33,34)$ genes. CpGenome universal methylated DNA (Chemicon International Inc., Temecula, CA) was used as the methylationpositive control and PBMCs from healthy volunteers were used as negative controls. PCR products were electrophoresed on a $2 \%$ agarose gel, stained with ethidium bromide and visualized with a UV illuminator.

Evaluation of H. pylori infection. H. pylori infection status was analyzed by PCR methods. The PCR conditions and primer sets have been described previously (43). The primer sequence is listed in Table I. H. pylori genomic DNA (ATCC43504) was used as a positive control.

Statistical analysis. Statistical analysis was performed by using the Welch's t-test and two-tailed Fisher's exact test. SPSS software (version 11.5J, Chicago, IL) was used to perform the analysis.

\section{Results}

Methylation status of gastric MALT lymphoma and related diseases. Initially, we examined whether the aberrant DNA methylation in gastric lymphomas could be detected by MSP. $\mathrm{CpG}$ island methylation was analyzed in the promoter region of 11 tumor-related genes ( 15, p16, kip2, p73, DAPK, hMLH-1, MGMT, HCAD, MINT1, MINT2 and MINT31) in gastric lymphoma specimens (15 DLBCLs, 21 L-MALT lymphomas and 5 H-MALT lymphomas) and also nonlymphoma controls ( 8 specimens of $\mathrm{CR}$ after eradication therapy; 5 specimens of NEM in the stomach, including chronic gastritis; and PBMCs from 10 healthy volunteers).

Representative results of MSP are shown in Fig. 1. CpGenome was used as the MSP-positive control. DNA methylation was categorized in 5 groups $(-, \pm,+,++$ and $+++)$ according to the signal intensity; ' - ' is no methylation signal; ' \pm ', very faint signal; + to +++ , evident signal with different strengths. Only the categories from + to +++ were regarded as methylation-positive. Table II shows a clear difference in the methylation frequencies between the lymphoma and control groups.

The number of methylated genes shifted from low to high values according to the disease progression from healthy controls to L-MALT lymphoma and H-MALT lymphoma and DLBCL (Fig. 2A). The average number of methylated genes in each group is: healthy PBMCs, 0.4; NEM, 0.4; CR after eradication therapy, $1.4 ; H$. pylori (-) L-MALT lymphoma, 3.5; H. pylori (+) L-MALT lymphoma, 5.5; H-MALT lymphoma, 7.8; and DLBCL, 6.4 (Fig. 2B). The number of 
Table I. Primer sequences and PCR conditions for MSP analysis.

\begin{tabular}{|c|c|c|c|}
\hline \multirow[b]{2}{*}{ Genes } & \multicolumn{2}{|c|}{ Primer sequences } & \multirow{2}{*}{$\begin{array}{l}\text { Annealing } \\
\text { temperature } \\
\text { in }{ }^{\circ} \mathrm{C} \text { (no } \\
\text { of cycles) }\end{array}$} \\
\hline & Primer sequences $\left(5^{\prime}-3^{\prime}\right)$ forward & Primer sequences $\left(5^{\prime}-3^{\prime}\right)$ reverse & \\
\hline \multirow[t]{2}{*}{ KIP2 } & MF 5'-ACACAACACACTTAACCTATAA-3' & MR 5'-CGCGGTCGTTAATTAGTCGC-3' & $56(38)$ \\
\hline & UF 5'-ACACAACGCACTTAACCTATAA-3' & UR 5'-TTTGTTTTGTGGTTGTTAATTAGTTGT-3' & $56(40)$ \\
\hline \multirow[t]{2}{*}{ p16 } & MF 5'-TTATTAGAGGGTGGGGCGGATCGC-3' & MR 5'-GACCCCGAACCGCGACCGTAA-3' & $66(35)$ \\
\hline & UF 5'-TTATTAGAGGGTGGGGTGGATTGT-3' & UR 5'-CAACCCCAAACCACAACCATAA-3' & $66(35)$ \\
\hline \multirow[t]{2}{*}{$h M L H-1$} & MF 5'-TTAATAGGAGAGGCGGATAGC-3' & MR 5'-CTATAAATTACTAAATCTCTTCG-3' & $54(35)$ \\
\hline & UF 5'-TTAATAGGAAGAGTGGATAGTG-3' & UR 5'-TCTATAAATTACTAAATCTCTTCA-3' & $54(35)$ \\
\hline \multirow[t]{2}{*}{ p15 } & MF 5'-GCGTTCGTATTTTGCGGTT-3' & MR 5'-CGTACAATAACCGAACGACCGA-3' & $65(35)$ \\
\hline & UF 5'-TGTGATGTGTTTGTATTTTGTGGTT-3' & UR 5'-CCATACAATAACCAAACAACCAA-3' & $60(35)$ \\
\hline \multirow[t]{2}{*}{$p 73$} & MF 5'-GGACGTAGCGAAATCGGGGTTC-3' & MR 5'-ACCCCGAACATCGACGTCCG-3' & $63(35)$ \\
\hline & UF 5'-AGGGGATGTAGTGAAATTGGGGTTT-3' & UR 5'-ATCACAACCCCAAACATCAACATCCA-3' & $66(35)$ \\
\hline \multirow[t]{2}{*}{$D A P K$} & MF 5'-GGATAGTCGGATCGAGTTAACGTC-3' & MR 5'-CCCTCCCAAACGCCGA-3' & $64(35)$ \\
\hline & UF 5'-GGAGGATAGTTGGATTGAGTTAATGTT-3' & UR 5'-CAAATCCCTCCCAAACACCAA-3' & $64(35)$ \\
\hline \multirow[t]{2}{*}{$M G M T$} & MF 5'-TTTCGACGTTCGTAGGTTTTCGC-3' & MR 5'-GCACTCTTCCGAAAACGAAACG-3' & $66(35)$ \\
\hline & UF 5'-TTTGTGTTTTGATGTTTGTAGGTTTTTGT-3' & UR 5'-AACTCCACACTCTTCCAAAAACAAAACA-3' & $-3^{\prime} 66(35)$ \\
\hline \multirow[t]{2}{*}{ MINT1 } & MF 5'-AATTTTTTTATATATATTTTCGAAGC-3' & MR 5'-AAAAACCTCAACCCCGCG-3' & $57(35)$ \\
\hline & UF 5'-AACAAAAAACCTCAACCCCACA-3' & UR 5'-AATTTTTTTATATATATTTTTGAAGTGT-3' & $57(35)$ \\
\hline \multirow[t]{2}{*}{ MINT2 } & MF 5'-TTGTTAAAGTGTTGAGTTCGTC-3' & MR 5'-AATAACGACGATTCCGTACG-3' & $61(35)$ \\
\hline & UF 5'-GATTTTGTTAAAGTGTTGAGTTTGT' & UR 5'-CAAAATAATAACAACAATTCCATACA-3' & $61(35)$ \\
\hline \multirow[t]{2}{*}{ MINT31 } & MF 5'-TGTTGGGGAAGTGTTTTTCGGC-3' & MR 5'-CGAAAACGAAACGCCGCG-3' & $64(35)$ \\
\hline & UF 5'-TAGATGTTGGGGAAGTGTTTTTTGGT-3' & UR 5'-TAAATACCCAAAAACAAAACACCACA-3' & $64(35)$ \\
\hline \multirow[t]{3}{*}{$H C A D$} & 1st F 5'-TTGGAAAAGTGGAATTAGTTGG-3' & 1st R 5'-CCTCTTCCCTACCTAAAACA-3' & $54(35)$ \\
\hline & MF 5'-TCGCGGGGTTCGTTTTTCGC-3' & MR 5'-GACGTTTTCATTCATACACGCG-3' & $69(25)$ \\
\hline & UF 5'-GTAAAATGAGGGAGTGTTAGG-3' & UR 5'-AAACACACCCAACAACCCCTCT-3' & $50(25)$ \\
\hline H.pylori & F 5'-ATTACTGACGCTGATTGTGC-3' & R 5'-CTGGAGAGACTAAGCCCTCC-3' & $60(40)$ \\
\hline
\end{tabular}

$\mathrm{U}$, unmethylated sequences and $\mathrm{M}$, methylated sequences.

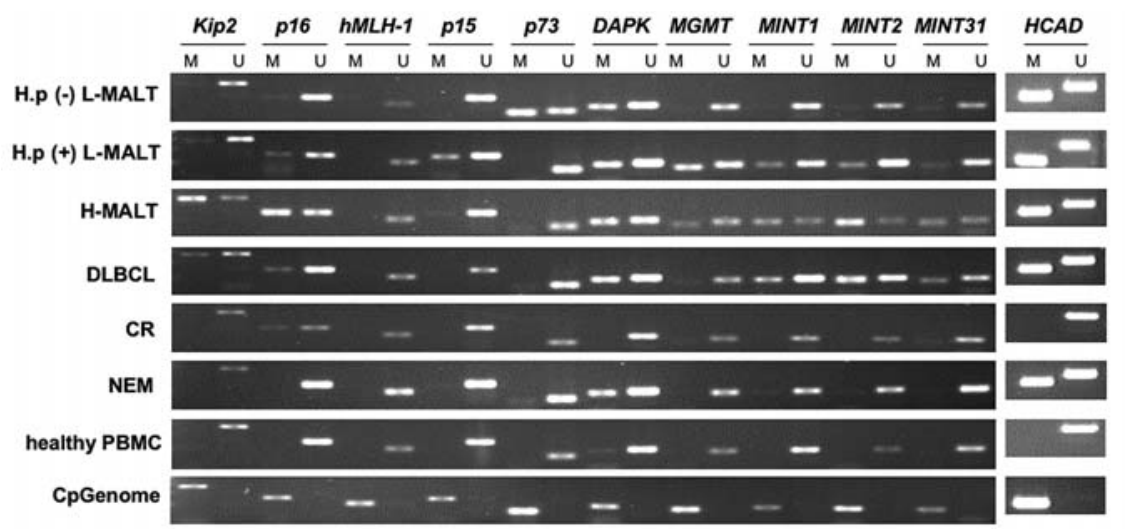

Figure 1. Representative results of methylation-specific PCR of 11 genes in low-grade MALT lymphoma (L-MALT), high-grade MALT lymphoma (H-MALT), diffuse large B-cell lymphoma (DLBCL), complete remission of MALT lymphoma (CR) after eradication therapy, no evidence of malignancy (NEM). Healthy PBMCs, used as negative control; CpGenom, used as positive control; M, methylated DNA and U, unmethylated DNA.

methylated genes was significantly greater in the lymphoma group compared to the control group $(\mathrm{P}<0.001$, Kruskal-Wallis exact test). Interestingly, the frequency of methylated genes in $\mathrm{CR}$ patients after eradication therapy remarkably decreased, suggesting that aberrant DNA methylation was closely associated with the $H$. pylori infection. 
Table II. Methylation profile of 11 genes in gastric lymphomas and related diseases.

\begin{tabular}{|c|c|c|c|c|c|c|c|c|c|c|c|c|c|c|c|c|}
\hline \multirow{7}{*}{\multicolumn{2}{|c|}{\begin{tabular}{|l|} 
\\
H-MALT \\
\end{tabular}}} & \multirow{2}{*}{\multicolumn{2}{|c|}{$\begin{array}{l}\text { agesesex } \\
76, \mathrm{~F}\end{array}$}} & \multirow{2}{*}{$\begin{array}{c}\text { H.p } \\
+\end{array}$} & KIP2 & p16 & hMLH-I & p15 & p73 & DAPK & MGMT & MINTI & MINT2 & MINT31 & HCAD & No of methylated genes \\
\hline & & & & & $-1+$ & + & - & $-1+$ & - & + & ++ & - & + & + & - & 5 \\
\hline & & 2 & $49 / \mathrm{MI}$ & + & H+H & H+H & - & - & - & ++ & + & + & H+H & ++ & +++ & 8 \\
\hline & & 3 & $70 \% \mathrm{~F}$ & + & + & H+ & - & - & + & H+ & H+ & $H$ & $\mathrm{HH}$ & + & $\mathrm{H+}$ & 9 \\
\hline & & 4 & $88 \mathrm{MI}$ & + & + & + & - & - & - & + & + & + & + & + & +++ & 8 \\
\hline & & 5 & $64 / \mathrm{M}$ & + & H+ & H+ & - & - & $+1+$ & H & t+ & + & H+H & + & +++ & 9 \\
\hline & & & H.MALT tot & & $80 \%(4 / 5)$ & $100 \%(5 / 5)$ & $0 \%(0 / 5)$ & $0 \%(0 / 5)$ & $40 \mathrm{~S}(2 / 5)$ & $100 \%(5 / 5)$ & $100 s(5 / 5)$ & $80 \%(4 / 5)$ & 100 (5/5) & $100 \mathrm{~F}(5 / 5)$ & $80 \%(45)$ & $100 \%(5 / 5)$ \\
\hline & & 1 & $58 \%$ & + & + & - & - & - & - & $-1+$ & $-1+$ & $-1+$ & + & + & ++ & 4 \\
\hline & & 2 & $55 / \mathrm{M}$ & + & $+H$ & - & - & $-1+$ & ++1 & + & $-1+$ & + & - & + & +++ & 6 \\
\hline & & 3 & $4 \mathrm{~L} / \mathrm{M}$ & + & + & $-1+$ & - & - & - & + & - & + & HH & + & $\mathrm{H++}$ & 6 \\
\hline & & 4 & $61 / F$ & + & + & + & + & - & $+H$ & $-1+$ & - & + & ++ & + & ++ & 8 \\
\hline & & 5 & $63 \mathrm{M}$ & + & - & - & + & ++ & - & + & $-1+$ & + & $+H$ & + & ++ & 7 \\
\hline & & 6 & $66 / \mathrm{M}$ & + & + & H & + & - & - & $-1+$ & +++ & + & $H+H$ & $-1+$ & $-1+$ & 6 \\
\hline & & 7 & $62 \mathrm{M}$ & + & + & H+t & - & + & $+H+$ & + & + & + & ++ & + & +++ & 10 \\
\hline DLL & CL & 8 & $79 / \mathrm{M}$ & + & + & H+ & - & + & - & + & + & + & + & + & - & 8 \\
\hline DLt & CL & 9 & $71 / F$ & + & $-1+$ & H+t & - & - & $\mathrm{H+}$ & + & + & + & + & + & +H+ & 8 \\
\hline & & 10 & $50 / \mathrm{M}$ & + & - & - & - & +++ & - & + & + & $-1+$ & + & - & +++ & 5 \\
\hline & & 11 & $73 / \mathrm{F}$ & + & + & $+1+$ & - & - & - & - & ++ & $-1+$ & + & $-1 t$ & $\mathrm{t+H}$ & 5 \\
\hline & & 12 & $76 / \mathrm{F}$ & + & $-1+$ & $+1+$ & - & - & - & - & $-1+$ & - & + & $-1+$ & - & 2 \\
\hline & & 13 & $62 \mathrm{~F}$ & + & + & + & - & - & - & ++ & - & + & + & + & ++ & 7 \\
\hline & & 14 & $7 \mathrm{~L} / \mathrm{M}$ & + & $H$ & - & - & - & + & +++ & - & + & + & + & $\mathrm{H+H}$ & 7 \\
\hline & & 15 & $5 \mathrm{~L} / \mathrm{M}$ & + & + & + & - & - & - & +++ & $-1+$ & + & + & + & +++ & 7 \\
\hline & & & DLBCL tota & & $73,3 \%(11 / 15)$ & \begin{tabular}{|l|}
$60 \%(9 / 15)$ \\
\end{tabular} & $20 \%(3 / 15)$ & $26.7 \%(4 / 15)$ & $33.3 \%(5 / 5)$ & 66.7\%(10/15) & \begin{tabular}{|l|}
$40 \%(6 / 5)$ \\
\end{tabular} & $73.3 \%(11 / 15)$ & $93,3 \%(14 / 5)$ & $73.3 \%(11 / 15)$ & \begin{tabular}{|l|}
$80 \%(12 / 15)$ \\
\end{tabular} & $93.3 \%(14 / 15)$ \\
\hline & & & ageosex & H.p & KIP2 & p16 & hMLH-I & p15 & $\mathrm{p} 73$ & DAPK & MGMT & MINTI & MINT2 & MINT31 & HCAD & No of methylated genes \\
\hline & & 1 & $34 / F$ & - & - & $-1+$ & - & - & - & - & $-1+$ & - & $-1+$ & - & $4+4$ & 1 \\
\hline & & 2 & $47 / \mathrm{F}$ & - & + & $-1+$ & - & - & - & $-1+$ & $-1+$ & - & $-1+$ & - & $+H$ & 2 \\
\hline & & 3 & $48 \mathrm{~F}$ & - & + & $-1+$ & - & - & + & + & - & - & - & $-1+$ & +++ & 4 \\
\hline & & 4 & $47 / \mathrm{F}$ & - & - & + & - & $-1+$ & - & $-1+$ & $-1+$ & - & - & - & +++ & 2 \\
\hline & & 5 & $54 / \mathrm{F}$ & - & + & +++ & - & + & - & + & $-1+$ & $-1+$ & $+H$ & + & $+H$ & 7 \\
\hline & & 6 & $62 \mathrm{M}$ & - & $+H$ & ++ & - & $-1+$ & +++ & ++ & + & $-1+$ & $+1+$ & + & +++ & 8 \\
\hline & H.p(-) & 7 & $75 \mathrm{M}$ & - & - & + & - & - & - & + & - & + & - & $-1 t$ & + & 4 \\
\hline & & 8 & $69 \mathrm{M}$ & - & - & $-1+$ & - & - & - & + & + & - & $-1+$ & $-1+$ & - & 2 \\
\hline & & 9 & $76 \mathrm{M}$ & - & - & - & - & - & - & $-1+$ & $-1+$ & - & - & $-1+$ & H & 1 \\
\hline & & 10 & $80 \mathrm{M}$ & - & - & - & - & - & - & $-1 t$ & - & - & - & - & - & 0 \\
\hline L-MALT & & II & $68 \mathrm{~F}$ & - & + & + & - & - & + & ++ & + & + & + & + & $H$ & 9 \\
\hline & & 12 & $67 / \mathrm{F}$ & - & - & $-1+$ & - & - & - & ++ & $-1+$ & - & - & $-1+$ & + & 2 \\
\hline & & & ALT H.p(-)t & & $41.7 \%(5 / 12)$ & $41.7 \xi_{(5 / 12)}$ & $0 \%(0 / 12)$ & $8.3 \epsilon_{(1 / 12)}$ & $16.7 \%(2 / 12)$ & $58.3 \%(7 / 12)$ & $25 \%(3 / 12)$ & $16.7 \%(2 / 2)$ & $25 \%(3 / 12)$ & $25 \%(3 / 12)$ & \begin{tabular}{|l|}
$33 \%(10 / 12)$ \\
\end{tabular} & $41.7 \varepsilon_{(5 / 12)}$ \\
\hline & & 13 & $54 / 7$ & + & +++ & + & - & $-1+$ & - & + & + & $-1+$ & $+H$ & + & $+H$ & 7 \\
\hline & & 14 & $55 / \mathrm{F}$ & + & + & + & - & $-1+$ & - & + & $-1+$ & $-1+$ & + & + & t+H & 6 \\
\hline & & 15 & $57 / \mathrm{F}$ & + & $H+$ & $+H+$ & - & - & - & + & $-1+$ & $-1+$ & + & + & t+H & 6 \\
\hline & & 16 & $34 / \mathrm{F}$ & + & - & $-1+$ & - & - & - & +++ & + & + & - & $-1+$ & + & 4 \\
\hline & & 17 & $57 / \mathrm{F}$ & + & +++ & + & - & - & - & + & + & $-1+$ & + & + & $H+$ & 7 \\
\hline & H.p(t) & 18 & $70 / \mathrm{F}$ & + & H+ & +++ & - & - & ++ & + & + & $-1+$ & $+H$ & ++ & $+H$ & 8 \\
\hline & & 19 & $74 / \mathrm{M}$ & + & $-1+$ & + & - & + & - & + & + & $-1+$ & + & - & +++ & 6 \\
\hline & & 20 & $62 \mathrm{~F}$ & + & - & + & - & - & - & + & + & $-1+$ & - & - & ++ & 4 \\
\hline & & 21 & $63 / \mathrm{M}$ & + & - & $-1+$ & - & - & - & + & + & - & - & $-1+$ & - & 2 \\
\hline & & & ALT H.p $(+)$ & & $556 \mathrm{k}(599)$ & $77.8 \%(7.9)$ & $0 \%(09)$ & $11.1 \%(1 / 9)$ & $11.1 \%(19)$ & \begin{tabular}{|c|}
$1005(9 / 9)$ \\
\end{tabular} & $77.8 \%(7 / 9)$ & $11.1 \%(1 / 9)$ & $66.7 \%(699)$ & $55.65(5 / 9)$ & $88.9 \xi_{2}(89)$ & $88.9 \%(8.9)$ \\
\hline & & & L-MALT tot & & $47.6 \%(10 / 21)$ & $57.1 \%(12 / 21)$ & $05(021)$ & $9.5 \%(2 / 21)$ & $14.3 \%(3 / 21)$ & $76.2 \%(1621)$ & $47.6 \div(10 / 21)$ & $14.3 \times(3 / 21)$ & $42.9 \%(9 / 21)$ & $38.1 \%(8 / 2)$ & $85.7 \%(1821)$ & $61.9 \%(13 / 21)$ \\
\hline & & & ageiser & H.p & KIP2 & p16 & hMLH-I & p15 & $\mathrm{p} 73$ & DAPK & MGMT & MINTI & MINT2 & MINT31 & HCAD & No of methylated genes \\
\hline & & 1 & $53 \mathrm{~F}$ & - & - & $-1+$ & - & $-1+$ & - & + & $-1+$ & - & H & $-1+$ & ++ & 3 \\
\hline & & 2 & $53 \mathrm{~F}$ & - & - & - & - & - & - & + & - & - & + & - & + & 3 \\
\hline & & 3 & $69 / \mathrm{M}$ & - & - & - & - & - & - & + & - & - & - & - & $-1+$ & 1 \\
\hline CF & & 4 & $76 \mathrm{M}$ & - & - & - & - & - & - & + & + & - & - & - & - & 2 \\
\hline & & 5 & $64 \mathrm{M}$ & - & - & - & - & - & - & - & - & - & - & - & - & 0 \\
\hline & & 6 & $64 \mathrm{M}$ & - & - & $-1+$ & - & - & - & - & - & - & - & $-1+$ & - & 0 \\
\hline & & 7 & $81 / M$ & - & - & + & - & - & - & - & - & - & - & - & - & 1 \\
\hline & & 8 & 7a:M & - & - & $-1+$ & - & - & - & $-1+$ & - & - & - & - & ++ & 1 \\
\hline & & & CR total & & $0 \bar{c}(08)$ & 12.5 द्र(1/8) & $0 \%(0.8)$ & $0 \%(0.8)$ & $0 \%(0.8)$ & $505(48)$ & $12.5 \%(1 / 8)$ & $0 \%(0.8)$ & $25 \%(28)$ & $0 \%(0.8)$ & $37.5 \%(38)$ & $0 \approx(0.8)$ \\
\hline & & 1 & $53 \mathrm{~F}$ & - & - & - & - & - & - & $-1+$ & - & - & - & - & - & 0 \\
\hline & & 2 & $54 \mathrm{~F}$ & + & - & - & - & - & - & $-1+$ & - & $-1+$ & - & - & - & 0 \\
\hline $\mathrm{NE}$ & & 3 & $56 / \mathrm{F}$ & - & - & - & - & - & - & $-1 t$ & - & $-1+$ & - & - & $\mathrm{HH}$ & 1 \\
\hline & & 4 & 55/M & - & - & - & - & - & - & - & - & - & $-1+$ & - & + & 1 \\
\hline & & 5 & $38 \mathrm{M}$ & - & - & - & - & - & - & - & - & - & - & - & $-1+$ & 0 \\
\hline & & & NEM total & & $0 \%(0.5)$ & $0 \%(0.5)$ & $0 \%(0.5)$ & $0 \%(0,05)$ & $0 \%(0.5)$ & $05(0.5)$ & $0 \%(0.5)$ & $0 \mathrm{Cr}(0.5)$ & $0 \%(0.5)$ & $0 \%(0.5)$ & $40 \%(25)$ & $0 \mathrm{E} ; 0.53$ \\
\hline & & 1 & $48 \mathrm{M}$ & nd & - & - & - & - & - & $-1+$ & - & - & - & - & - & 0 \\
\hline & & 2 & $29 / \mathrm{M}$ & nd & - & - & + & - & - & $-1+$ & - & + & - & - & $-1+$ & 2 \\
\hline & & 3 & $46 / \mathrm{M}$ & nd & - & - & - & - & - & - & - & - & - & - & $-1+$ & 1 \\
\hline & & 4 & $27 / \mathrm{F}$ & nd & - & - & - & - & - & - & - & - & - & - & - & 0 \\
\hline & & 5 & $24 \mathrm{~F}$ & nd & - & - & - & - & - & - & - & - & - & - & - & 0 \\
\hline Healthy & PBMC & 6 & $27 / \mathrm{F}$ & nd & - & + & - & - & $-1 t$ & - & - & - & - & - & - & 1 \\
\hline & & 7 & $20 \mathrm{MM}$ & nd & - & - & - & - & - & $-1 t$ & - & - & - & - & - & 0 \\
\hline & & 8 & $41 / M$ & nd & - & - & - & - & $-1 t$ & - & - & - & - & - & $-1+$ & 0 \\
\hline & & 9 & $41 / M$ & nd & - & $-1+$ & - & - & $-1+$ & - & - & - & - & - & - & 0 \\
\hline & & 10 & soM & nd & - & - & - & - & + & - & - & - & - & - & - & 1 \\
\hline & & & PBMC total & & 0 OF(0/10) & \begin{tabular}{|l|}
$10 \%(1 / 10)$ \\
\end{tabular} & $10 \%(1 / 10)$ & $0 \%(0,10)$ & $10 \%(\mathrm{~L} / 10)$ & $0 \%(0,10)$ & $0 \%(0 / 10)$ & \begin{tabular}{ll|}
$10 \%(\mathrm{~V} / 10)$ \\
\end{tabular} & $0 \%(0 / 10)$ & $\theta S(\theta-10)$ & 0 - & $0 S \varepsilon(0 / 0)$ \\
\hline
\end{tabular}

Results of MSP were shown as -, -/+, +, ++, or +++ according to the signal intensity. DLBCL, diffuse large B-cell lymphoma; H-MALT, highgrade MALT lymphoma; MALT, MALT lymphoma; CR, complete remission of MALT lymphoma; NEM, no evidence of malignancy in stomach; PBMCs, healthy donor peripheral blood mononuclear cells. The number of methylated genes was shown in the right-end column. CIMP (+) was defined as more than or equal to 4 genes were methylated. Hp, H. pylori infection. nd: not done.

An analysis of the differences in methylation frequency of the 11 genes among various stages of gastric MALT lymphomas and related diseases revealed a statistically significant difference in the DNA methylation incidence between the lymphoma and control groups, especially in the Kip2,p16,DAPK, MGMT, MINT1, MINT2 and MINT31 genes 
A

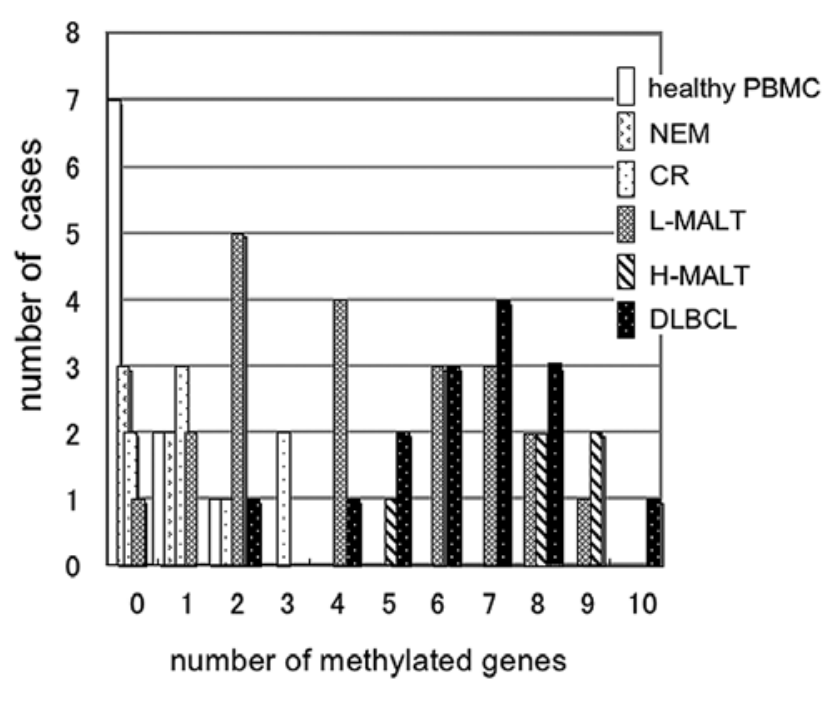

B

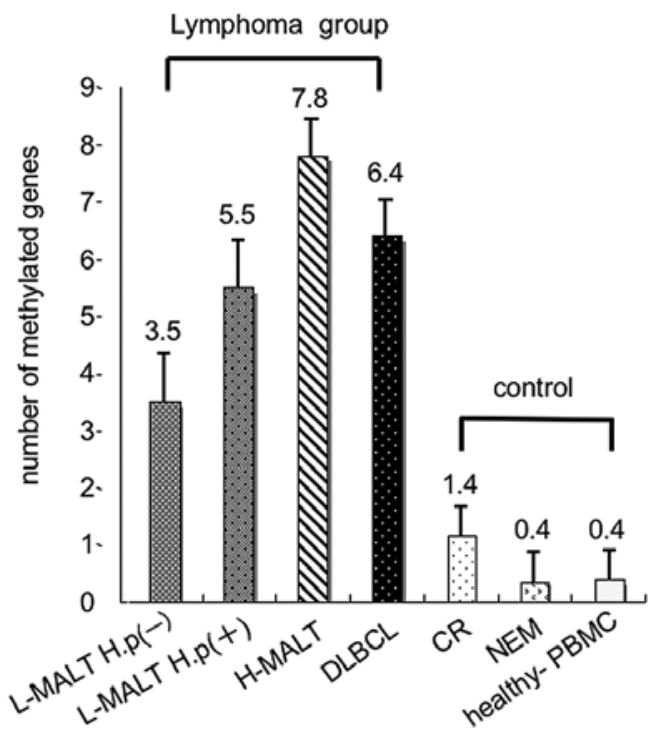

Figure 2. (A) The distribution of number of methylated genes in gastric lymphomas. The distribution profile of the methylated genes shifted from low to high according to the disease progression from healthy donor, NEM and CR to lymphoma groups from low-grade L-MALT to high-grade H-MALT and DLBCL. (B) The average number of methylated genes in lymphoma and control groups. Significant difference of average number of methylated genes was detected between lymphoma and control groups $(\mathrm{P}<0.001$, Kruskal-Wallis exact test).

(Table III), suggesting that aberrant $\mathrm{CpG}$ methylation of particular genes was closely associated with the lymphomagenesis in the stage-specific manner.

CIMP in gastric lymphoma. An examination of the number of methylated genes among gastric lymphomas and controls revealed a clear boundary (between 3 and 4 methylated genes) in the distribution of the number of methylated genes (Fig. 3A). All specimens with $\geq 4$ methylated genes belong to the lymphoma group. On the other hand, almost all of the specimens with $<4$ methylated genes were in the control group. Therefore, we defined the CIMP-positive specimens as those specimens with at least 4 methylated genes. Specimens with $<4$ methylated genes were CIMP-negative. The CIMP (+) or (-) status in the lymphoma and control groups is summarized in Fig. 3B, indicating that $93.3 \%$ (14 of 15 ) of DLBCL, $100 \%$ (5 of 5) of H-MALT lymphoma and $61.9 \%$ (13 of 21) of L-MALT lymphoma were CIMP-positive. Contrary, all specimens of CR ( 8 of 8 ), NEM (5 of 5) and healthy PBMCs (10 of 10) were CIMP-negative. The incidence of CIMP (+) specimens was significantly higher in the lymphoma group than in the control group $(\mathrm{P}<0.001$, two-tailed Fisher's exact test). CIMP-positive specimens increased according to the disease progression from L-MALT lymphoma to H-MALT lymphoma and to DLBCL.

Next, we analyzed the correlation between CIMP status and the methylation of each gene (Table IV). Methylation of all genes except for the $h M L H 1$ gene was correlated with CIMP status $(\mathrm{P}<0.004$, Fisher's exact test). There was a statistically significant difference in the incidence of CIMP between the two stages of MALT lymphoma and related diseases, such as between healthy PBMCs and L-MALT $(\mathrm{P}=0.001)$; healthy PBMCs and H-MALT $(\mathrm{P}=0.000)$; healthy PBMCs and DLBCL (P=0.000); and NEM and H-MALT
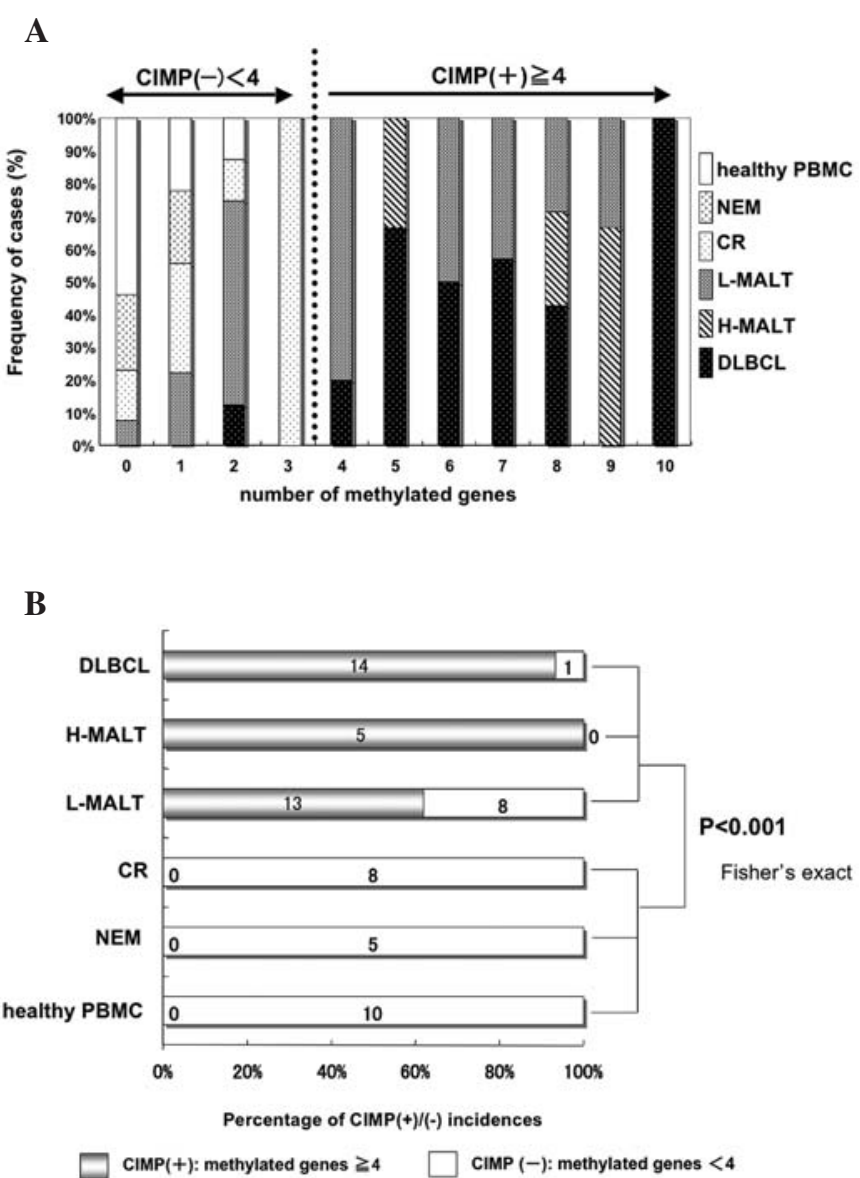

Figure 3. (A) Case frequency (\%) of number of methylated genes among gastric lymphomas and controls including healthy donors, NEM and CR after eradication. (B) CIMP (+) or (-) status in lymphoma and control groups. The incidence of CIMP (+) specimens was significantly higher in lymphoma group than control group ( $\mathrm{P}<0.001$, two-tailed Fisher's exact test). The number in each column indicates the number of specimens. 
Table III. Statistical differences in methylation frequency of 11 genes between various stages of gastric MALT lymphoma and related diseases $\left(\mathrm{P}-\right.$ values $\left.^{\mathrm{a}}\right)$.

\begin{tabular}{|c|c|c|c|c|c|c|c|c|c|c|c|}
\hline & Kip2 & p15 & pl6 & $p 73$ & $h M L H 1$ & $D A P K$ & $M G M T$ & $H C A D$ & MINTI & MINT2 & MINT3I \\
\hline $\begin{array}{l}\text { Healthy PBMC } \\
\text { NEM }\end{array}$ & - & - & 1.000 & 1.000 & 1.000 & - & - & 0.095 & 1.000 & - & - \\
\hline $\begin{array}{l}\text { Healthy PBMC } \\
\text { Low MALT }\end{array}$ & 0.012 & 1.000 & 0.020 & 1.000 & 0.323 & 0.000 & 0.012 & 0.000 & 1.000 & 0.030 & 0.032 \\
\hline $\begin{array}{l}\text { Healthy PBMC } \\
\text { High MALT }\end{array}$ & 0.004 & - & 0.002 & 0.242 & 1.000 & 0.000 & 0.000 & 0.004 & 0.017 & 0.000 & 0.000 \\
\hline $\begin{array}{l}\text { Healthy PBMC } \\
\text { DLBCL }\end{array}$ & 0.001 & 0.125 & 0.018 & 0.345 & 0.626 & 0.001 & 0.051 & 0.000 & 0.004 & 0.000 & 0.001 \\
\hline $\begin{array}{l}\text { Healthy PBMC } \\
\text { CR }\end{array}$ & - & - & 1.000 & 1.000 & 1.000 & 0.023 & 0.444 & 0.069 & 1.000 & 0.183 & - \\
\hline $\begin{array}{l}\text { Healthy PBMC } \\
\mathrm{Hp}(+)\end{array}$ & 0.000 & 0.302 & 0.001 & 0.400 & 1.000 & 0.000 & 0.001 & 0.000 & 0.024 & 0.000 & 0.000 \\
\hline $\begin{array}{l}\text { Healthy PBMC } \\
\mathrm{Hp} \mathrm{(-)}\end{array}$ & 0.040 & 1.000 & 0.162 & 0.594 & 0.455 & 0.005 & 0.221 & 0.000 & 1.000 & 0.221 & 0.221 \\
\hline $\begin{array}{l}\text { NEM } \\
\text { Low MALT }\end{array}$ & 0.121 & 1.000 & 0.042 & 0.555 & - & 0.004 & 0.121 & 0.062 & 1.000 & 0.129 & 0.281 \\
\hline $\begin{array}{l}\text { NEM } \\
\text { High MALT }\end{array}$ & 0.048 & - & 0.008 & 0.444 & - & 0.008 & 0.008 & 0.524 & 0.048 & 0.008 & 0.008 \\
\hline $\begin{array}{l}\text { NEM } \\
\text { DLBCL }\end{array}$ & 0.008 & 0.530 & 0.038 & 0.266 & 0.539 & 0.033 & 0.260 & 0.131 & 0.008 & 0.000 & 0.008 \\
\hline $\begin{array}{l}\text { NEM } \\
\text { CR }\end{array}$ & - & - & 1.000 & - & - & 0.105 & 1.000 & 1.000 & - & 0.487 & - \\
\hline $\begin{array}{l}\text { NEM } \\
\mathrm{Hp}(+)\end{array}$ & 0.007 & 1.000 & 0.005 & 0.309 & 1.000 & 0.001 & 0.016 & 0.072 & 0.046 & 0.000 & 0.005 \\
\hline $\begin{array}{l}\text { NEM } \\
\text { Hp (-) }\end{array}$ & 0.245 & 1.000 & 0.245 & 0.515 & - & 0.044 & 0.515 & 0.117 & 1.000 & 0.515 & 0.515 \\
\hline $\begin{array}{l}\text { Low MALT } \\
\text { High MALT }\end{array}$ & 0.330 & 1.000 & 0.129 & 0.558 & - & 0.545 & 0.053 & 1.000 & 0.010 & 0.042 & 0.039 \\
\hline $\begin{array}{l}\text { Low MALT } \\
\text { DLBCL }\end{array}$ & 0.176 & 0.210 & 1.000 & 0.443 & 0.064 & 0.709 & 0.741 & 0.677 & 0.001 & 0.004 & 0.049 \\
\hline $\begin{array}{l}\text { Low MALT } \\
\text { CR }\end{array}$ & 0.027 & 1.000 & 0.044 & 0.552 & - & 0.209 & 0.110 & 0.019 & 0.540 & 0.671 & 0.066 \\
\hline $\begin{array}{l}\text { High MALT } \\
\text { DLBCL }\end{array}$ & 1.000 & 0.530 & 0.260 & 1.000 & 0.539 & 0.266 & 0.038 & 1.000 & 1.000 & 1.000 & 0.530 \\
\hline $\begin{array}{l}\text { High MALT } \\
\text { CR }\end{array}$ & 0.007 & - & 0.005 & 0.128 & - & 0.105 & 0.005 & 0.266 & 0.007 & 0.021 & 0.001 \\
\hline $\begin{array}{l}\text { DLBCL } \\
\text { CR }\end{array}$ & 0.001 & 0.257 & 0.074 & 0.122 & 0.526 & 0.657 & 0.345 & 0.071 & 0.001 & 0.002 & 0.001 \\
\hline $\begin{array}{l}\text { CR } \\
\mathrm{Hp}(+)\end{array}$ & 0.001 & 0.564 & 0.004 & 0.160 & 1.000 & 0.078 & 0.019 & 0.021 & 0.006 & 0.002 & 0.000 \\
\hline $\begin{array}{l}\text { CR } \\
\text { Hp (-) }\end{array}$ & 0.055 & 1.000 & 0.325 & 0.242 & - & 1.000 & 0.619 & 0.062 & 0.495 & 1.000 & 0.242 \\
\hline $\begin{array}{l}\mathrm{Hp}(+) \\
\mathrm{Hp}(-)\end{array}$ & 0.161 & 0.651 & 0.083 & 1.000 & 0.543 & 0.124 & 0.043 & 1.000 & 0.038 & 0.000 & 0.013 \\
\hline $\begin{array}{l}\text { Low MALT Hp (+) } \\
\text { Low MALT Hp (-) }\end{array}$ & 0.670 & 1.000 & 0.184 & 0.603 & - & 0.045 & 0.030 & 1.000 & 1.000 & 0.087 & 0.203 \\
\hline
\end{tabular}
with large cell compornent. Bold numbers indicate significant differences of methylation frequency $(\mathrm{P}<0.05)$. 
Table IV. Correlation between presence of CIMP and methylation of each gene.

\begin{tabular}{|c|c|c|c|c|}
\hline & & \multicolumn{2}{|c|}{ CIMP } & \multirow[b]{2}{*}{ P-value } \\
\hline & & Positive & Negative & \\
\hline \multirow[t]{2}{*}{ Kip2 } & Methylated & 24 & 1 & 0.000 \\
\hline & Unmethylated & 8 & 31 & \\
\hline \multirow[t]{2}{*}{$p 15$} & Methylated & 6 & 0 & 0.002 \\
\hline & Unmethylated & 26 & 32 & \\
\hline \multirow[t]{2}{*}{ p16 } & Methylated & 24 & 4 & 0.000 \\
\hline & Unmethylated & 8 & 28 & \\
\hline \multirow[t]{2}{*}{$p 73$} & Methylated & 11 & 1 & 0.003 \\
\hline & Unmethylated & 21 & 31 & \\
\hline \multirow[t]{2}{*}{$h M L H 1$} & Methylated & 3 & 1 & 0.613 \\
\hline & Unmethylated & 29 & 31 & \\
\hline \multirow[t]{2}{*}{$D A P K$} & Methylated & 28 & 7 & 0.000 \\
\hline & Unmethylated & 5 & 24 & \\
\hline \multirow[t]{2}{*}{$M G M T$} & Methylated & 19 & 3 & 0.000 \\
\hline & Unmethylated & 13 & 29 & \\
\hline \multirow[t]{2}{*}{$H C A D$} & Methylated & 29 & 10 & 0.000 \\
\hline & Unmethylated & 3 & 22 & \\
\hline \multirow[t]{2}{*}{$M I N T 1$} & Methylated & 18 & 1 & 0.000 \\
\hline & Unmethylated & 14 & 31 & \\
\hline \multirow[t]{2}{*}{$M I N T 2$} & Methylated & 28 & 3 & 0.000 \\
\hline & Unmethylated & 5 & 28 & \\
\hline \multirow[t]{2}{*}{ MINT31 } & Methylated & 24 & 0 & 0.000 \\
\hline & Unmethylated & 8 & 32 & \\
\hline
\end{tabular}

${ }^{\mathrm{a}}$ Fisher's exact test.

$(\mathrm{P}=0.008)$ (Table $\mathrm{V})$, indicating that the incidence of CIMP in each lymphoma group was significantly higher than that of the control group.

Effects of $H$. pylori infection on the number of methylated genes and CIMP. We analyzed the effects of $H$. Pylori infection on the number of methylated genes and CIMP status (Fig. 4). The distribution of the number of methylated genes with or without $H$. pylori infection in MALT lymphoma indicates that the number of methylated genes was shifted to a higher value in cases of $H$. pylori infection (Fig. 4A). The CIMP (+) incidence was significantly higher in H. Pylori (+) L-MALT $(89 \%, 8 / 9)$ compared to H. Pylori (-) L-MALT $(42 \%, 5 / 12)(\mathrm{P}=0.037)$ (Fig. 4B). H. Pylori $(+)$ gastric lymphoma also showed significantly higher CIMP (+) incidence $(93 \%, 27 / 29)$ than H. Pylori (-) gastric lymphoma $(42 \%, 5 / 12)(\mathrm{P}<0.001)$ (Fig. 4C). Table VI shows a more detailed statistical analysis of the effects of $H$. pylori infection on the particular target gene methylation. The methylation frequency of specific genes, such as $p 16, D A P K, M G M T$, Kip2, MINT2, MINT31 and HCAD, significantly increased in H. pylori (+) L-MALT compared to healthy PMBCs $(\mathrm{P}<0.05)$. On the other hand, the methylation frequency of these genes (except for the MINT2 gene) dramatically decreased in CR after eradication therapy compared to $H$. pylori (+) L-MALT
Table V. Statistical difference in the incidence of CIMP among various stages of MALT lymphoma and related diseases.

\begin{tabular}{|c|c|c|c|}
\hline & \multicolumn{2}{|c|}{ CIMP } & \multirow[b]{2}{*}{ P-value } \\
\hline & Positive & Negative & \\
\hline Healthy PBMC & 0 & 10 & - \\
\hline NEM & 0 & 5 & \\
\hline Healthy PBMC & 0 & 10 & 0.001 \\
\hline Low MALT & 13 & 8 & \\
\hline Healthy PBMC & 0 & 10 & 0.000 \\
\hline High MALT & 5 & 0 & \\
\hline Healthy PBMC & 0 & 10 & 0.000 \\
\hline DLBCL & 14 & 1 & \\
\hline Healthy PBMC & 0 & 10 & - \\
\hline $\mathrm{CR}$ & 0 & 8 & \\
\hline Healthy PBMC & 0 & 10 & 0.000 \\
\hline Hp (+) & 27 & 2 & \\
\hline Healthy PBMC & 0 & 10 & 0.040 \\
\hline Hp (-) & 5 & 7 & \\
\hline NEM & 0 & 5 & 0.039 \\
\hline Low MALT & 8 & 13 & \\
\hline NEM & 0 & 5 & 0.008 \\
\hline High MALT & 5 & 0 & \\
\hline NEM & 0 & 5 & 0.000 \\
\hline DLBCL & 14 & 1 & \\
\hline NEM & 0 & 5 & - \\
\hline $\mathrm{CR}$ & 0 & 8 & \\
\hline NEM & 0 & 5 & 0.000 \\
\hline $\mathrm{Hp}(+)$ & 27 & 2 & \\
\hline NEM & 0 & 5 & 0.515 \\
\hline Hp (-) & 5 & 7 & \\
\hline Low MALT & 13 & 8 & 0.281 \\
\hline High MALT & 5 & 0 & \\
\hline Low MALT & 13 & 8 & 0.051 \\
\hline DLBCL & 14 & 1 & \\
\hline Low MALT & 13 & 6 & 0.003 \\
\hline CR & 0 & 8 & \\
\hline High MALT & 5 & 0 & 1.000 \\
\hline DLBCL & 14 & 1 & \\
\hline High MALT & 5 & 0 & 0.001 \\
\hline CR & 0 & 8 & \\
\hline DLBCL & 14 & 1 & 0.000 \\
\hline CR & 0 & 8 & \\
\hline $\mathrm{CR}$ & 0 & 8 & 0.000 \\
\hline $\mathrm{Hp}(+)$ & 27 & 2 & \\
\hline $\mathrm{CR}$ & 0 & 8 & 0.055 \\
\hline Hp (-) & 5 & 7 & \\
\hline $\mathrm{Hp}(+)$ & 27 & 2 & 0.001 \\
\hline Hp (-) & 5 & 7 & \\
\hline
\end{tabular}

${ }^{\text {a}}$ Fisher's exact test. Hp (+), H. pylori (+) MALT lymphoma with/ without large cell component and DLBCL; Hp (-), H. pylori (-) MALT lymphoma with/without large cell component and DLBCL; NEM, no evidence for malignancy; low MALT, MALT lymphoma; high MALT, MALT lymphoma with large cell component. 


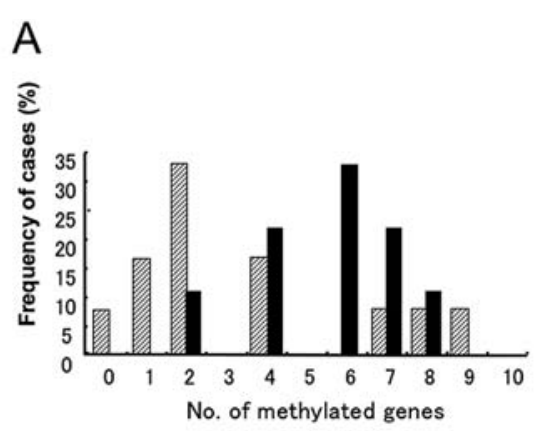

MALT H.p (-) MALT H.p (+)
B

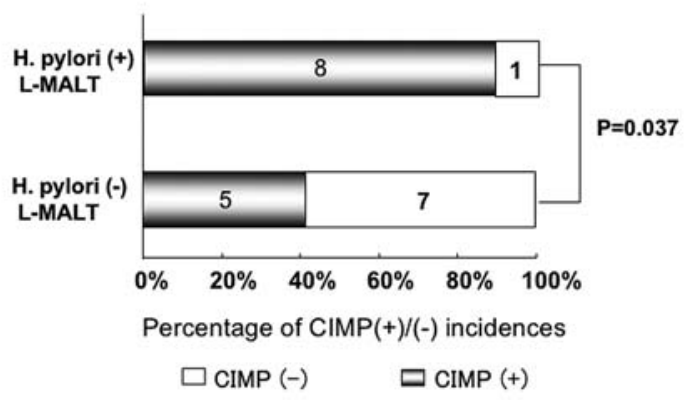

C

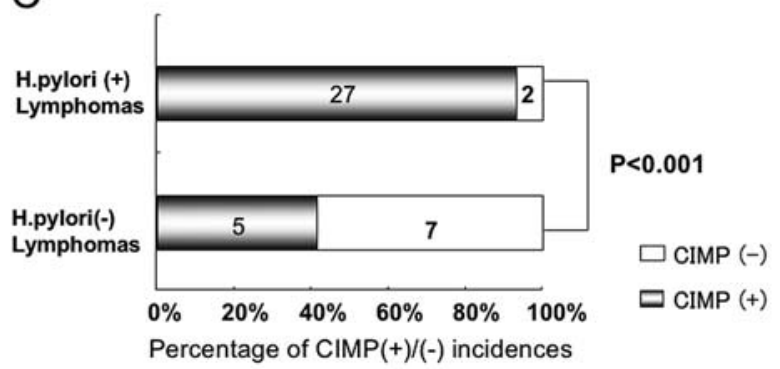

Figure 4. Association of H. Pylori infection with the number of methylated genes and CIMP status. (A) Distribution of number of methylated genes with/without $H$. pylori infection in MALT lymphoma. Profile of number of methylated genes was shifted to higher value of number of methylated genes according to the $H$. pylori infection. (B) Correlation between CIMP (+)/(-) status and H. pylori infection to low-grade MALT. The incidence of CIMP (+) specimens was significantly higher in $H$. pylori $(+)$ L-MALT than $H$. pylori $(-)$ L-MALT $(\mathrm{P}=0.037$, two-tailed Fisher's exact test). (C) The incidence of CIMP $(+)$ specimens was significantly higher in $H$. pylori (+) gastric lymphoma than $H$. pylori (-) gastric lymphoma, including MALT lymphoma, high-grade MALT lymphoma and DLBCL. ( $\mathrm{P}<0.001$, two-tailed Fisher's exact test).

A

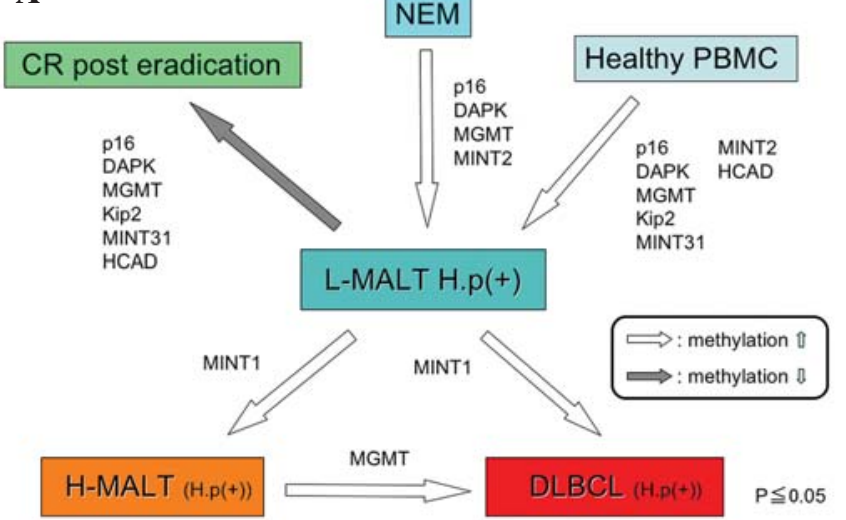

B

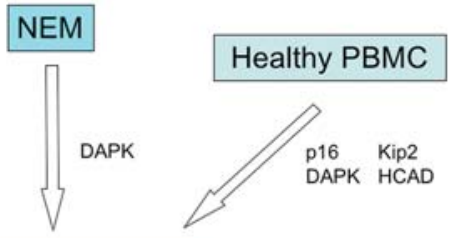

L-MALT H.p(-)

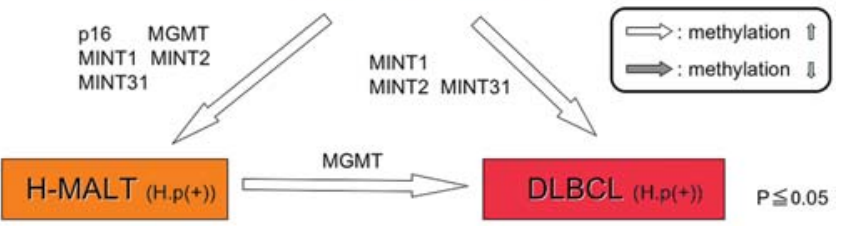

Figure 5. Schematic illustration of development and progression of gastric lymphoma in terms of specific gene methylation. Genes associated with white arrow indicate significant increase of methylation frequency from arrow start point status to end point status. On the other hand, genes associated with dark arrow show statistically significant decrease of methylation frequency from start-point to end-point status $(\mathrm{P}<0.05)$. (A) Schematic illustration of $H$. pylori (+) L-MALT related diseases in terms of CpG hypermethylation. (B) Schematic illustration of $H$. pylori (-) L-MALT-related diseases in terms of CpG hypermethylation. Statistical data was originated from Tables III and VI.

$(\mathrm{P}<0.05)$. These statistically significant alterations in the methylation frequency of the 11 genes among various clinical states, including MALT lymphoma with or without $H$. pylori infection and related diseases, are summarized in Fig. 5A and $B$.

\section{Discussion}

A close link between $H$. pylori infection and the development of gastric MALT lymphoma has been established by the detection of $H$. pylori infection in most patients of gastric MALT lymphoma $(1,2,19,20)$. We previously reported that autoimmune reactions evoked by immunological crossreactivity between $H$. pylori HSP60 and host HSP60 are important in the development of gastric MALT lymphoma because of the molecular mimicry between human HSP60 and H. pylori HSP60 (44-47).

In the present study, we investigated the aberrant DNA hypermethylation in gastric lymphoma, including L-MALT lymphoma, H-MALT lymphoma and DLBCL, showing that 
Table VI. Statistical differences of methylation frequency in 11 genes between various clinical status and $H$. pylori infection ( \pm ) low grade MALT lymphoma $\left(\mathrm{P}-\right.$ values $\left.^{\mathrm{a}}\right)$.

\begin{tabular}{|c|c|c|c|c|c|c|c|c|c|c|c|}
\hline \multirow[t]{2}{*}{ Low MALT HP (+) } & \multicolumn{11}{|c|}{ Statistical differences of methylation frequency between two groups } \\
\hline & Kip2 & p15 & p16 & $p 73$ & $h M L H 1$ & $D A P K$ & $M G M T$ & $H C A D$ & MINT1 & MINT2 & MINT31 \\
\hline $\begin{array}{l}\text { Low MALT HP (+) } \\
\text { Healthy PBMC }\end{array}$ & 0.011 & 0.474 & 0.005 & 1.000 & 1.000 & 0.000 & 0.001 & 0.000 & 1.000 & 0.003 & 0.011 \\
\hline $\begin{array}{l}\text { Low MALT HP (+) } \\
\text { NEM }\end{array}$ & 0.086 & 1.000 & 0.021 & 1.000 & - & 0.000 & 0.021 & 0.095 & 1.000 & 0.031 & 0.086 \\
\hline $\begin{array}{l}\text { Low MALT HP (+) } \\
\text { High MALT }\end{array}$ & 0.580 & 1.000 & 0.505 & 0.505 & - & - & 0.505 & 1.000 & 0.023 & 0.258 & 0.221 \\
\hline $\begin{array}{l}\text { Low MALT HP (+) } \\
\text { DLBCL }\end{array}$ & 0.412 & 0.615 & 0.657 & 0.351 & 0.266 & 0.118 & 0.105 & 1.000 & 0.009 & 0.130 & 0.412 \\
\hline $\begin{array}{l}\text { Low MALT HP (+) } \\
\text { CR }\end{array}$ & 0.029 & 1.000 & 0.015 & 1.000 & - & 0.029 & 0.015 & 0.050 & 1.000 & 0.153 & 0.029 \\
\hline \multirow[t]{2}{*}{ Low MALT HP (-) } & \multicolumn{11}{|c|}{ Statistical differences of methylation frequency between two groups } \\
\hline & Kip2 & p15 & pl6 & $p 73$ & $h M L H 1$ & $D A P K$ & $M G M T$ & $H C A D$ & MINT1 & MINT2 & MINT31 \\
\hline $\begin{array}{l}\text { Low MALT HP (-) } \\
\text { Healthy PBMC }\end{array}$ & 0.040 & 1.000 & 0.040 & 0.594 & 0.455 & 0.005 & 0.221 & 0.000 & 1.000 & 0.221 & 0.221 \\
\hline $\begin{array}{l}\text { Low MALT HP (-) } \\
\text { NEM }\end{array}$ & 0.245 & 1.000 & 0.245 & 0.515 & - & 0.044 & 0.515 & 0.117 & 1.000 & 0.515 & 0.515 \\
\hline $\begin{array}{l}\text { Low MALT HP (-) } \\
\text { High MALT }\end{array}$ & 0.294 & 1.000 & 0.044 & 0.600 & - & 0.245 & 0.009 & 1.000 & 0.028 & 0.009 & 0.009 \\
\hline $\begin{array}{l}\text { Low MALT HP (-) } \\
\text { DLBCL }\end{array}$ & 0.130 & 0.342 & 0.449 & 0.698 & 0.231 & 0.706 & 0.683 & 1.000 & 0.006 & 0.001 & 0.021 \\
\hline $\begin{array}{l}\text { Low MALT HP (-) } \\
\text { CR }\end{array}$ & 0.055 & 1.000 & 0.325 & 0.242 & - & 1.000 & 0.619 & 0.062 & 0.495 & 1.000 & 0.242 \\
\hline
\end{tabular}

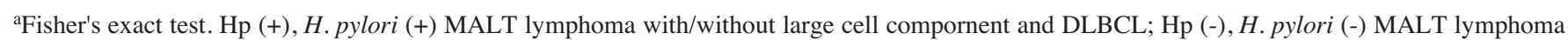
with/without large cell compornent and DLBCL; NEM, no evidence for malignancy; low MALT, MALT lymphoma; high MALT, MALT lymphoma with large cell compornent. Bold numbers indicate significant differences of methylation frequency $(\mathrm{P}<0.05)$.

the number of methylated genes is clearly greater in the lymphoma group as compared to the control group (Fig. 2A and $\mathrm{B}$ ). Furthermore, according to the progression from LMALT to H-MALT and to DLBCL, the number of methylated genes shifted from low to high values, indicating that the aberrant hypermethylated genes accumulated in the course of disease progression. There was a significant difference in the incidence of CIMP between the lymphoma group and the control group (Fig. 3B), suggesting that there are abnormalities in the regulatory and/or maintenance mechanism of DNA methylation status that cause aberrant hypermethylation to accumulate in specific genes in gastric lymphomas.

Interestingly, a specific group of genes was targeted for aberrant hypermethylation in a stage-specific manner in gastric lymphoma progression and related diseases (Tables III and VI and Fig. 5A and B). The group of genes, including Kip2, p16, DAPK, HCAD, MGMT, MINT2 and MINT31, was significantly hypermethylated during the onset of $H$. pylori (+) L-MALT from healthy PBMCs (Table V, Fig. 5A). The same group of genes (except for the MINT2) was significantly de-methylated in the CR state post-eradication therapy from $H$. pylori (+)
L-MALT (Table VI, Fig. 5A); these results clearly indicate that aberrant DNA hypermethylation of these set of genes is closely associated with $H$. pylori infection and also the onset of $H$. pylori (+) L-MALT $(\mathrm{P} \leq 0.05)$. They suggest that abnormal epigenetic alterations, such as the aberrant DNA hypermethylation that was induced by $H$. pylori infection, are responsible for the triggering of $H$. pylori (+) L-MALT. Aberrant hypermethylation of MINT1 is significantly associated with the progression from $H$. pylori (+) L-MALT to H. pylori (+) H-MALT or DLBCL $(\mathrm{P}=0.023$ or $\mathrm{P}=0.009$ respectively, Table VI, Fig. 5A). Aberrant hypermethylation of $M G M T$ was also closely associated with the progression from $H$. pylori $(+)$ H-MALT to DLBCL $(\mathrm{P}=0.038$, Table III, Fig. 5A).

On the other hand, a small number of genes, including $p 16$, Kip2, DAPK and HCAD, were associated with the onset of H. pylori (-) L-MALT from healthy PBMCs, suggesting that these genes contribute to the triggering of $H$. pylori (-) LMALT independent of $H$. pylori infection (Table VI, Fig. 5B). In the progression from $H$. pylori (-) L-MALT to $H$. pylori (+) H-MALT, another group of genes, such as p16, MGMT, 
MINT1, MINT2 and MINT31, were significantly hypermethylated (Table VI, Fig. 5B). This process was associated with $H$. pylori infection, which was closely similar to the methylation profile alteration at the onset of $\mathrm{H}$. pylori $(+)$ L-MALT from healthy PBMC accompanied with the $H$. pylori infection. The aberrant hypermethylation of MINT1 was significantly associated with the progression from L-MALT to H-MALT and also to DLBCL (Table III, Fig. 5B). Similarly, $M G M T$ hypermethylation was significantly associated with the progression from H-MALT to DLBCL (Table III), comparing the H.pylori (+) L-MALT process (Fig. 5A) with the H.pylori (-) L-MALT process (Fig. 5B), it is clear that hypermethylation of specific target genes, such as $\mathrm{p} 16$, MGMT, MINT2 and MINT31, is closely associated with $H$. pylori infection. It suggests the possibility that $H$. pylori infection perturbs or alters the epigenetic status, including the methylation profile, with the production of $H$. pylorispecific molecules, such as $\operatorname{CagA}$, VacA, OipA and DNA methyltransferase (hpylM or hpyIIM) $(48,49)$, cytokines or inflammatory responses with the production of reactive oxygen species to cause aberrant hypermethylation of specific genes, followed by malignant transformation events including aberrant hypermethylation of other genes, alteration of miRNA expression profile, histone modification and/or chromatin organization changes. Contact of $H$. pylori with the epithelium induces transcription of the induced-by-contact-withepithelium gene (iceAl); the presence of this gene product has been associated with duodenal ulceration and gastric adenocarcinoma (50). The expression of $H$. pylori methyltransferase hpylM accompanies iceAl (48). H. pylori DNA methyltransferases may be one candidate to cause aberrant hypermethylation in addition to host DNA methyltransferases. The effectiveness of $H$. pylori eradication therapy in $H$. pylori (+) L-MALT is consistent with the reversibility of epigenetic modifications and alterations (including DNA methylation) in response to micro-environmental conditions, nutrition and drugs.

Our findings strongly suggest that $H$. pylori infection causes the aberrant DNA hypermethylation of specific genes and induces CIMP, an important epigenetic mechanism of the development and progression of gastric MALT lymphoma. The genes that were specifically hypermethylated by the $H$. pylori infection and disease progression could be used as highly sensitive epigenetic markers to detect $H$. pylori infection and the development and progression of gastric lymphoma, as well as to monitor the disease status.

\section{Acknowledgements}

We gratefully acknowledge Okayama University Hospital, National Hospital Organization Fukuyama Medical Center, National Hospital Organization Okayama Medical Center, Okayama Saiseikai General Hospital, Toyama Prefectural Central Hospital, Chugoku Central Hospital and Okayama Red Cross General Hospital for generously supplying the patient specimens. We also acknowledge Ms. Mutsumi Okabe, Ms. Hiromi Nakamura and Ms. Miyuki Shiotani (Department of Pathology, Okayama University Medical School) for their excellent technical assistance. Grant number: The Ministry of Education, Culture, Sports, Science and Technology of Japan
\#12670161 (to T.O.) and the Ministry of Health, Labor and Welfare of Japan (to T.Y.).

\section{References}

1. Isaacson PG and Wright DH: Malignant lymphoma of mucosaassociated lymphoid tissue: A distinctive type of B-cell lymphoma. Cancer 52: 1410-1416, 1983.

2. Isaacson PG and Spencer J: The biology of low grade MALT lymphoma. J Clin Pathol 48: 395-397, 1995.

3. Parsonnet $J$ and Isaacson PG: Bacterial infection and MALT lymphoma. N Engl J Med 350: 213-215, 2004

4. Ferreri AJ, Guidoboni M, Ponzoni M, et al: Evidence for an association between Chlamydia psittaci and ocular adnexal lymphomas J Natl Cancer Inst 96: 586-594, 2004.

5. Cerroni L, Zochling N, Putz B, et al: Infection by Borrelia burgdorferi and cutaneous B-cell lymphoma. J Cutan Pathol 24: 457-461, 1997.

6. Negri E, Little D, Boiocchi M, et al: B-cell non-Hodgkin's lymphoma and hepatitis $C$ virus infection: A systemic review. Int J Cancer 111: 1-8, 2004.

7. Tursi A, Brandimarte $\mathrm{G}$ and Torello M: Disappearance of gastric mucosa-associated lymphoid tissue in hepatitis $\mathrm{C}$ virus-positive patients after anti-hepatitis $\mathrm{C}$ virus therapy. J Clin Gastroenterol 38: 360-363, 2004.

8. Ferraccioli GF, Sorrentino D, De Vita S, et al: B cell clonality in gastric lymphoid tissues of patients with Sjogren's syndrome. Ann Rheum Dis 55: 311-316, 1996.

9. Strubel B, Huber D, Wohrer S, et al: Frequency of chromosomal aberrations involving MALT1 in mucosa-associated lymphoid tissue lymphoma in patients with Sjogren's syndrome. Clin Cancer Res 10: 476-480, 2004.

10. Ye H, Gong L, Liu H, et al: MALT lymphoma with $\mathrm{t}(14 ; 18)$ (q32;q21)/IGH-MALT1 and BCL10 expression. J Pathol 205: 293-301, 2005.

11. Streubel B, Simonitsch-Klupp I, Mullauer L, et al: Variable frequencies of MALT lymphoma-associated genetic aberrations in MALT lymphomas of different sites. Leukemia 18: 1722-1726, 2004.

12. Auer IA, Gascoyne RD, Connors JM, et al: $\mathrm{t}(11 ; 18)(\mathrm{q} 21 ; \mathrm{q} 21)$ is the most common translocation in MALT lymphomas. Ann Oncol 8: 979-985, 1997.

13. Ott G, Katzenberger T, Greiner A, et al: The $\mathrm{t}(11 ; 18)(\mathrm{q} 21 ; \mathrm{q} 21)$ chromosome translocation is a frequent and specific aberration in low-grade lymphomas but not high grade malignant nonHodgikin's lymphomas of the mucosa-associated lymphoid tissue (MALT-) type. Cancer Res 57: 3944-3948, 1997.

14. Wotherspoon AC, Soosay GN, Diss TC, et al: Low-grade primary B-cell lymphoma of the lung: An immunohistochemical, molecular, and cytogenetic study of a single specimen. Am J Clin Pathol 94: 655-660, 1990.

15. Ye H, Dogan A, Karran L, et al: BCL10 expression in normal and neoplastic lymphoid tissue: Nuclear localization in MALT lymphoma. Am J Pathol 157: 1147-1154, 2000.

16. Streubel B, Lamprecht A, Dierlamm J, et al: T(14;18)(q32;q21) involving IGH and MALT1 is a frequent chromosomal aberration in MALT lymphoma. Blood 101: 2335-2339, 2003.

17. Streubel B, Vinatzer U, Lamprecht A, et al: T(3;14)(p14.1;q32) involving IGH and FOXP1 is a novel recurrent chromosomal aberration in MALT lymphoma. Leukemia 19: 652-658, 2005.

18. Barrans SL, Fentom JA, BAnham A, et al: Strong expression of FOXP1 identifies a distinct subset of diffuse large b-cell lymphoma (DLBCL) patients with poor outcome. Blood 104: 2933-2935, 2004.

19. Dierlamm J, Baens M, Wlodarska I, et al: The apoptosis inhibitor gene API2 and novel $18 \mathrm{q}$ gene, MLT, are recurrently rearranged in the $\mathrm{t}(11 ; 18)(\mathrm{q} 21 ; \mathrm{q} 21)$ associated with mucosa-associated lymphoid tissue lymphomas. Blood 93: 3601-3609, 1999.

20. Akagi T, Motegi M, Tamura A, et al: A novel gene, MALT1 at $18 \mathrm{q} 21$, is involved in $\mathrm{t}(11 ; 18)(\mathrm{q} 21 ; \mathrm{q} 21)$ found in low-grade $\mathrm{B}$ cell lymphoma of mucosa-associated lymphoid tissue. Oncogene 18: 5785-5794, 1999.

21. Peng H, Du M, Diss TC, et al: Genetic evidence for a clonal link between low and high-grade components in gastric MALT B-cell lymphoma. Histopathology 30: 425-429, 1997.

22. Remstein ED, James CD and Kurtin PJ: Incidence and subtype specificity of API2-MALT1 fusion translocations in extranordal, nordal, and splenic marginal zone lymphomas. Am J Pathol 156: 1183-1188, 2000. 
23. Chuang JC and Jones PA: Epigenetics and MicroRNAs. Pediatr Res 61: 24-29, 2007.

24. Plass C: Cancer epigenomics. Hum Mol Genet 11: 2479-2488, 2002.

25. Kaneko Y, Sakurai S, Hironaka M, et al: Distinct methylated profiles in Helicobacter pylori dependent and independent gastric MALT lymphomas. Gut 52: 641-646, 2003.

26. Jones PA and Takai D: The role of DNA methylation in mammalian epigenetics. Science 293: 1068-1070, 2001.

27. Kaneda M, Okano M, Hata K, Sado T, et al: Essential role for de novo DNA methylatransferase Dnmt3a in paternal and maternal imprinting. Nature 429: 900-903, 2004.

28. Csankovszki G, Nagy A and Jaenisch R: Synergism of Xist RNA, DNA methylation, and histone hypoacetylation in maintaining X chromosome inactivation. J Cell Biol 153: 773-784, 2001.

29. Meissner A, Mikkelsen TS, Gu H, Wernig M, et al: Genomescale DNA methylation maps of pluripotent and differentiated cells. Nature 454: 766-771, 2008

30. Oka T, Yoshino T, Hayashi K, et al: Reduction of hematopoietic cell-specific tyrosine phosphatase SHP-1 gene expression in natural killer cell lymphoma and various types of lymphomas/ leukemias: Combination analysis with cDNA expression array and tissue microarray. Am J Pathol 159: 1495-1505, 2001.

31. Oka T, Ouchida M, Koyama M, et al: Gene silencing of the tyrosine phosphatase SHPl gene by aberrant methylation in leukemias/lymphomas. Cancer Res 62: 6390-6394, 2002.

32. Koyama M, Oka T, Ouchida M, Nakatani Y, Nishiuchi R, Yoshino T, Hayashi K, Akagi T and Seino Y: Activated proliferation of B-cell lymphomas/leukemias with the SHPI gene silencing by aberrant $\mathrm{CpG}$ methylation. Lab Invest 83: 1849-1858, 2003.

33. Toyota M, Ho C, Ahuja N, Jair KW, Li Q, Ohe-Toyota M, Baylin SB and Issa JP: Identification of differential methylated sequences in colorectal cancer by methylad $\mathrm{CpG}$ island amplification. Cancer Res 59: 2307-2312, 1999.

34. Toyota M, Ahuja N, Ohe-Toyota M, Herman JG, Baylin SB and Issa JP: $\mathrm{CpG}$ islands methylator phenotype in colorectal cancer. Proc Natl Acad Sci USA 96: 8681-8686, 1999.

35. An C, Choi IS, Yao JC, et al: Prognostic significance of $\mathrm{CpG}$ island methylator phenotype and microsatellite instability in gastric carcinoma. Clin Cancer Res 11: 656-663, 2005.

36. Herman JG, Graff JR, Myöhänen S, Nelkin BD and Bayyin SB: Methylation specific PCR: A novel PCR assay for methylation status of CpG islands. Proc Natl Acad Sci USA 93: 9821-9826, 1996.

37. Min KO, Seo EJ, Kwon HJ, Lee EJ, Kim WI, Kang CS and Kim KM: Methylation of $16^{\mathrm{INK} 4 \mathrm{~A}}$ and $\mathrm{p} 57^{\mathrm{KIP} 2}$ are involved in the development and progression of gastric MALT lymphomas. Mod Pathol 19: 141-148, 2006.

38. Esteller M, Hamilton SR, Burger PC, Baylin SB and Herman JG: Inactivation of the DNA repair gene $\mathrm{O}^{6}$-methylguanine-DNA methyltransferase by promoter hypermethylation is a common event in primary human neoplasia. Cancer Res 59: 793-797, 1999.
39. Christensen LL, Madsen BE, Wikman FP, et al: The association between genetic variants in hMLH1 and hMSH2 and the development of sporadic colorectal cancer in the Danish population. BMC Med Genet 9: 52, 2008.

40. Liu M, Taketani T, Li R, Takita J, Taki T, Yang H, Kawaguchi H, Ida K, Matsuo Y and Hayashi Y: Loss of p73 gene expression in lymphoid leukemia cells is associated with hyper mathylation. Leuk Res 25: 441-447, 2000.

41. Christoph F, Hinz S, Kempkensteffen C, et al: mRNA expression profiles of methylated APAF-1 and DAPK-1 tumor suppressor genes uncover clear cell renal cell carcinomas with aggressive phenotype. J Urol 178: 2655-2659, 2007.

42. Ogama Y, Ouchida M, Yoshino T, et al: Prevalent hypermethylation of the CDH13 gene promoter in malignant $\mathrm{B}$ cell lymphomas. Int J Oncol 25: 685-691, 2004.

43. Ho SA, Hoyle JA, Lewis FA, Secker AD, Cross D, Mapstone NP, Dixon MF, Wyatt JI, Tompkins DS, Taylor GR and Quirke P: Direct polymerase chain reaction test for detect of Helicobacter pylori in Human and Animals. J Clin Microbiol 29: 2543-2549, 1991.

44. Kobayashi K, Yokota K, Yoshino T, et al: Detection Helicobacter pylori associated antigen and heat shock protein 60 on follicular dendritic cells in the germinal centers of low grade B cell lymphoma of gastric mucosa associated lymphoid tissue (MALT). J Clin Pathol 51: 396-398, 1998.

45. Kawahara Y, Yokota K, Mizuno M, et al: Antibodies to human gastric epitherial cells and heat shock protein 60 in Helicobacter pylori positive mucosa associated lymphoid tissue lymphoma. Gut 45: 20-23, 1999.

46. Takenaka R, Yokota K, Mizuno M, et al: Serum antibodies to Helicobacter pylori heat shock protein 60 correlate with the response of gastric mucosa-associated lymphoid tissue lymphoma to eradication therapy of $H$. pylori. Helicobacter 9 : 194-200, 2004.

47. Yamasaki R, Yokota $\mathrm{K}$, Okada H, et al: Immune response in Helicobacter pylori-induced low-grade gastric-mucosa-associated lymphoid tissue (MALT) lymphoma. J Med Microbiol 53: 21-29, 2004.

48. Atherton JC: The pathogenesis of Helicobacter pylori-induced gastro-duodenal diseases. Annu Rev Pathol Mech Dis 1: 63-96, 2006.

49. Joanne L, Grant S, Lam E, et al: Characterization of the DNA adenine 5'GATC3' methylase HpyIIM from Helicobacter pylori. Curr Microbiol 49: 47-54, 2004.

50. Kidd M, Peek RM, Lastovica AJ, et al: Analysis of iceA genotypes in South Africa Helicobacter pylori strains and relationship to clinically significant disease. Gut 49: 629-635, 2001. 